\title{
CRÍTICA AL FUNCIONALISMO NORMATIVISTA
}

CRITICISM OF NORMATIVIST FUNCTIONALISM

Eduardo Demetrio Crespo*

RESUMO

El artículo gira en torno al modelo de pensamiento del funcionalismo "normativista" formulado por Günther Jakobs y de las bases metodológicas que han hecho desembocar su teoría de la pena en el ambiguo concepto del llamado "derecho penal del enemigo" como teoría de la excepción penal.

Palavras-chave: Funcionalismo normativista; teoria de la pena en Günther Jakobs; Derecho Penal del enemigo.

\section{ABSTRACT}

The article revolves around the "normative" model of functionalism formulated by Günther Jakobs and the methodological bases that took his theory of punishment to the ambiguous concept of the socalled "criminal law of the enemy" as a theory of criminal exception.

Keywords: Normative Functionalism; theory of grief in Günther Jakobs; criminal law of the enemy.

* Doutor em Direito pela Universidad de Salamanca (Espanha).

Professor Catedrático de Direito Penal da Universidad de Castilla-La Mancha (Espanha).

eduardo.demetrio@uclm.es

Recebido em 29-01-2018 | Aprovado em 29-01-2018

\begin{abstract}
${ }^{1}$ Artigo convidado. Texto revisado de la conferencia pronunciada en Lima el 01 de abril de 2009 en la Facultad de Derecho de la Pontificia Universidad Católica del Perú en el marco de las Jornadas 'Critica al normativismo funcionalista'. Publicado anteriormente em: Revista de Derecho penal y Criminología, MADRID, n. 3, 2010, p. 1326; MONTOYA, I. (coord.), Crítica al funcionalismo normativista y otros temas actuales del Derecho penal, Lima: Palestra y Pontificia Universidad Católica del Perú, 2011, p. 101-113; Sabadini, P. (comp.), Estudios críticos del Derecho penal moderno, Buenos Aires: Fabián J. Di Plácido, 2011, p. 17-30.
\end{abstract}




\section{SUMÁRIO}

\section{¿QUÉ CABE DENOMINAR COMO “FUNCIONALISMO" EN DERECHO PENAL?; 1 EL "FUNCIONALISMO NORMATIVISTA" EN JAKOBS; 2 PRINCIPALES CRÍTICAS AL FUNCIONALISMO NORMATIVISTA EN JAKOBS; 3 DE LA “SOCIEDAD SIN HOMBRES" DE NIKLAS LUHMANN AL “DERECHO PENAL DEL ENEMIGO” DE GÜNTHER JAKOBS; CONCLUSIONES.}

\section{¿ ¿UÉ CABE DENOMINAR COMO “FUNCIONALISMO” EN DERECHO PENAL?}

Se ha dicho que por funcionalismo cabe entender orientaciones de la dogmática jurídico-penal que intentan construir las categorías del sistema a partir de los fines del Derecho penal. No se trataría en este sentido de un fenómeno moderno, sino que se remontaría al menos a las sistemáticas teleológicas inspiradas en el neokantismo².

Ahora bien, dentro de este amplio marco se divisan distintos tipos de funcionalismo de corte muy diverso, que hay que distinguir necesariamente por conducir a consecuencias muy diferentes. Entre estos son especialmente relevantes el funcionalismo puramente político-criminal de Roxin y el funcionalismo de carácter sociológico o sistémico de Jakobs.

El pensamiento de Roxin es funcionalista porque busca -en el sentido antes expuestola acomodación del Derecho penal a ciertos fines y principios político-criminalmente asentados en la Constitución propia del Estado de Derecho ${ }^{3}$.

El pensamiento de Jakobs es funcionalista porque define el derecho como una prestación consistente en garantizar la identidad normativa y con ella la constitución misma de la sociedad. En este sentido se ha afirmado que la concepción de Jakobs "constituye el intento más radical y acabado hasta ahora de construir la teoría de la pena y del delito en términos de funcionalidad para el mantenimiento del sistema social"4.

Otros intentos destacables de incorporar al derecho penal una consideración sociológica de corte funcionalista han sido los de Callies y Amelung que -basándose en algunas aportaciones de la teoría de los sistemas sociales de Luhmann- relacionan delito y perturbación de funcionamiento del sistema social. También el pensamiento de Hassemer ha estado fuertemente influenciado por teorías sociológicas del control social.

\section{EL “FUNCIONALISMO NORMATIVISTA” EN JAKOBS}

El modelo dogmático propuesto por Jakobs se contrapone en esencia a la dogmática ontologicista de Welzel, frente a la cual propone una completa "renormativización" de los

\footnotetext{
2 SILVA SÁNCHEZ, Jesús Maria. Introducción, en B. Schünemann, El sistema moderno del Derecho penal: cuestiones fundamentales, Madrid: Tecnos, 1991, p. 19.

${ }^{3}$ CRESPO, Eduardo Demetrio. Culpabilidad y fines de la pena: con especial referencia al pensamiento de Claus Roxin. In: Revista Derecho Penal Contemporáneo, Bogotá, n. 25, p. 87-132, 2008.

${ }^{4}$ PEÑARANDA RAMOS, Enrique. Sobre la influencia del funcionalismo y la teoría de sistemas en las actuales concepciones de la pena y del concepto de delito, San Vicente del Raspeig: Universidad de Alicante, 2000, p. 291.
} 
conceptos jurídico-penales con el propósito de que puedan cumplir con la función que él atribuye a la pena, que no es otra que la "prevención general positiva" como ejercicio de reconocimiento de la norma (o garantía de la vigencia de las expectativas normativas) mediante tres elementos: a) ejercicio en la confianza en la norma; b) ejercicio de fidelidad en el derecho; y c) ejercicio de aceptación de las consecuencias ${ }^{5}$.

Como acertadamente ha señalado Peñaranda Ramos este esquema se corresponde con la relevancia cada vez menor que Jakobs atribuye a la relación interna entre el autor potencial del hecho y la norma, en aras de la significación social de la vigencia de las normas y su infracción ${ }^{6}$. Como consecuencia la pena no se dirige a prevenir futuras infracciones (al estilo de la prevención general negativa) sino que tiene por objeto restablecer según el pensamiento clásicamente hegeliano la vigencia de las normas quebrantadas. Se trataría en este sentido más de una teoría retributiva que preventiva ${ }^{7}$.

Esta idea ha sido aun más claramente perfilada por su discípulo Lesch al formular una "teoría funcional de la retribución" 8 en la que queda puesto de relieve que la única función de la pena es servir a la autoconfirmación de la identidad de la sociedad mediante la prestación de que los delitos dejen de concebirse como tales en el futuro.

De este modo Jakobs ha ido deconstruyendo el edificio sistemático de la teoría del delito en sus bases mismas a través del formalismo de las categorías y la utilización de conceptos vagos e imprecisos que carecen de capacidad de subsunción. Esto se muestra ya en la distinción entre injusto y culpabilidad, pues siendo lo decisivo el quebrantamiento y vigencia de la norma, la culpabilidad termina convirtiéndose en presupuesto de la acción, lo que conduce a su discípulo Lesch a formular incluso un "tipo total de culpabilidad". Característica esencial de este análisis funcional, cuyo método resulta de la combinación entre Heg'el y Luhmann, como ha destacado recientemente Schünemann, es que no se relaciona al hecho real de la lesión de un bien jurídico, sino solo a su relevancia comunicativa para la vigencia del Derecho en la sociedad 9 .

\section{PRINCIPALES CRÍTICAS AL FUNCIONALISMO NORMATIVISTA EN JAKOBS}

Algunas de las críticas más severas a la teoría de Jakobs fueron vertidas en su día por Baratta $^{10}$ acusándola de ser conservadora, tecnocrática e incluso autoritaria, favorecer la expansión del derecho penal y promover la reproducción ideológica y material de las relaciones sociales existentes, acogiendo lo peor de la teoría de sistemas de Luhmann.

\footnotetext{
${ }^{5}$ Vid. infra amplia bibliografía de G. Jakobs.

${ }^{6}$ PEÑARANDA, Op. cit., p.296.

${ }^{7}$ CRESPO, Eduardo Demetrio. Prevención general e individualización judicial de la pena, Salamanca: Ediciones Universidad de Salamanca, 1999.

8 LESCH. Der Verbrechensbegriff. Grundlinien einer funktionalen Revision, Köln. Berlin. Bonn. München: Heymann, 1999.

${ }^{9}$ SCHÜNEMANN, Bernd. El propio sistema de la teoría del delito. In: InDret: Revista para el análisis del derecho, Barcelona, v.1, p. 13, fev. 2008.

${ }^{10}$ BARATTA, Alessandro. Integración-prevención: una nueva fundamentación de la pena dentro de la teoría sistémica. In: RevicyhlUZ: Revistas Científicas e Humanísticas, Venezuela, n. 15, p. 2 - 26, 1987.
} 
El núcleo central de la argumentación anterior vincula el pensamiento de Jakobs a la teoría de los sistemas sociales de Niklas Luhmann, relación que no ha sido negada por el propio Jakobs, sino matizada, al tiempo que se reconoce asimismo la ascendencia de la tradición filosófica que se remota a Hegel e incluso el parentesco con la doctrina del "daño intelectual del delito" defendida significativamente por Francesco Carrara dentro de la Escuela clásica ${ }^{11}$.

Sin embargo, desde la Filosofía del Derecho, se pone en duda no solo la fidelidad con que las tesis de Luhmann se acogen en la Ciencia del Derecho Penal, sino que además se niega que las propuestas funcionales de la prevención general positiva identificadas como sistémicas lo sean realmente a partir del giro autopoiético que adopta la teoría de Luhmann a partir de los ochenta ${ }^{12}$.

Conviene pues examinar con algo de detalle en qué consiste esta relación:

a) Luhmann distingue entre "expectativas cognitivas" y "expectativas normativas". Jakobs entiende la norma como una expectativa de conducta que se estabiliza contrafácticamente. A su vez, Luhmann, como hace Jakobs, entiende que la sociedad se compone de comunicaciones y no de sujetos.

b) La "función" en Luhmann se refiere a un sistema diferenciado de comunicaciones en el seno de la sociedad como sistema general y omniabarcante, de modo que su clausura operativa o autopoiesis se cimenta sobre su cabal cumplimiento ${ }^{13}$. Es esta misma clausura operativa la que explica en Jakobs que el Derecho penal se conciba como un sistema de comunicaciones que atiende a la función de protección de expectativas normativas de conducta.

c) Solo la referencia al entorno -que da cuenta de la dimensión cognitiva del sistema jurídico- en el interior del sistema permite obtener la diferencia, a efectos de la autoobservación de las comunicaciones jurídicas, entre autorreferencia y heterorreferencia ${ }^{14}$. Para Prieto Navarro lo determinante es el modo en que ambas dimensiones, cognitiva y normativa, resultan combinadas a través de las operaciones del sistema ${ }^{15}$. Según este autor la exigencia de preservar la conciencia normativa frente al delito a través de la comunicación que representa la pena significa únicamente que la igualdad de la respuesta ha de garantizar las expectativas de los sujetos $^{16}$

d) El corolario es que el Derecho es indiferente ante los efectos psicológicos que su modo de operación pueda desplegar, consecuencia última de la concepción luhmaniana de la "sociedad sin hombres". Por su parte, una de las

\footnotetext{
${ }^{11}$ PEÑARANDA. Op. cit., p. 304.

12 PRIETO NAVARRO, Evaristo. Teoría de sistemas, funciones del Derecho y control social: perspectivas e imposibilidades para la dogmática penal. In: Revista DOXA, Alicante, n. 23, p. 265 - 288, 2000; GARCÍA AMADO, Juan Antonio. ¿Dogmática penal sistémica? Sobre la influencia de Luhmann en la teoría penal. In: Revista DOXA, Alicante, n. 23, p. $233-264,2000$.

13 PRIETO NAVARRO. Op. cit., p. 268.

${ }^{14}$ PRIETO NAVARRO. Op. cit., p. 271.

15 Ibid., p. 272.

${ }^{16}$ Ibid., p. 277.
} 
características básicas del sistema de Jakobs es la "ausencia de referentes externos al derecho positivo desde los que analizar críticamente las normas" ${ }^{17}$.

A partir de ahí Jakobs aborda desde un punto de vista absolutamente formal (neopositivismo formalista) la función del Derecho penal al preocuparse solo por la seguridad de las expectativas normativas sin que importe el contenido de las normas o los valores implicados ${ }^{18}$. Para Portilla Contreras el formalismo jurídico de Jakobs no solo representa una continuación de la tesis de Kelsen, sino que llega incluso a superar la teoría sistémica ${ }^{19}$.

De la crítica del formalismo se ha defendiendo el autor analizado diciendo que esto es algo propio de cualquier concepción con el grado de abstracción que la suya implica, lo que en realidad no resta un ápice de vigor a la crítica. Por otro lado, como con razón ha señalado Prieto Navarro, "ni cabe pedagogía a través del Derecho, pues eso rebasa con mucho sus competencias funcionales, ni puede alentarse una conciencia fiel al mismo"20.

Se aboca por esta vía a la crítica de la aparente "asepsia" de una construcción como la de Jakobs hacia las cuestiones de legitimidad del sistema normativo. Jakobs no desconoce este aspecto, si bien lo esquiva en el sentido de que para una teoría funcionalista las cuestiones de legitimación no pueden resolverse en el plano interno del Derecho penal. En este sentido se ha pronunciado también $M$ üssig ${ }^{21}$ al advertir que la cuestión de los criterios de legitimación material de las normas penales desbordarían el cauce formal de la prevención general positiva remitiendo al análisis de los criterios materiales de identidad de una sociedad determinada.

Otra crítica -desde la teoría de la norma- ha sido formulada por Peñaranda Ramos al señalar que las expectativas de conducta "no pueden ser contrafácticamente estabilizadas a la larga si la facticidad de la norma es continua y manifiestamente transgredida", por lo que la dirección de conductas debería ser una segunda función del derecho derivada de la anterior ${ }^{22}$. A esto dedicó también en parte su atención Luhmann en su obra Das Recht der Gesellschaft pronunciándose en sentido negativo: la probabilidad de sanciones pertenece al instrumental simbólico que permite reconocer si existe o no una expectativa en el sentido del derecho.

A este respecto se ha dicho que la prevención general positiva puede ofrecer sin embargo una visión más completa que la propia teoría de sistemas de Luhmann, de modo que la peculiaridad del modo de validez del derecho se orientaría simultáneamente a los dos polos: a) la facticidad de la observancia regular de las normas, obtenida en su caso mediante coerción, y b) la legitimidad de la regla misma, que produce su observancia por el propio respeto hacia ella ${ }^{23}$. De esta opinión se muestra en España Peñaranda Ramos que entiende que esto significaría con relación a la amenaza de la pena que "esta no puede ser de tal

\footnotetext{
${ }^{17}$ CONTRERAS, Guillermo Portilla. Los excesos de formalismo jurídico neofuncionalista en el normativismo del derecho penal. In: Revista General de Derecho Penal, Espanha, n. 4, p. 8, 2005.

${ }^{18} \mathrm{HIRSCH}$, Hans Joachim. El principio de culpabilidad y su función en el Derecho Penal. In: Revista Peruana de Ciencias Penales, Lima, n. 5, p. 179, jan. 1995.

${ }^{19}$ CONTRERAS. Op. cit., p. 2.

20 PRIETO NAVARRO. Op. cit., p. 285.

${ }^{21}$ MÜSSIG, Bernd. Schtuz abstrakter Rechtsgüter und abstrakter Rechtsgüterschtuz. Alemanha: Frankfurt Am Main: P. Lang, 1994.

22 PEÑARANDA. Op. cit., p. 315.

${ }^{23}$ HABERMAS, Jürgen. Facticidad y validez: sobre el derecho y el Estado democrático de derecho en términos de teoría del discurso. $5^{\circ}$. ed. Madrid: TROTTA, 2010. 696 p.
} 
intensidad que desplace en la práctica la posibilidad de que el cumplimiento se produzca por aquella motivación que no puede ser impuesta" 24 .

En esta línea de considerar la pena estatal como medio para fomentar un cumplimiento libre y voluntario de las normas se moverían asimismo propuestas como las de Baurman y Kuhlen. También la de Andrew von Hirsch, al entender la pena como desaprobación del hecho que, a su vez, suministra razones a su autor para desistir de su realización ${ }^{25}$. Pero se trataría aquí en todo caso de propuestas interpretativas muy diferentes a las del funcionalismo normativista que propone Günther Jakobs, en la que no queda ni rastro de algo tan fundamental en un Derecho penal del hecho, como es la protección de bienes jurídicos esenciales.

\section{DE LA "SOCIEDAD SIN HOMBRES" DE NIKLAS LUHMANN AL "DERECHO PENAL DEL ENEMIGO" DE GÜNTHER JAKOBS}

Uno de los excesos del neofuncionalismo penal ha consistido en la "normativización del concepto de persona", que ha permitido a Günther Jakobs distinguir entre un Derecho penal basado en acciones de personas y otro en acciones de "no personas" o "derecho penal del enemigo" 26 . Por mi parte, en trabajos anteriores, he defendido asimismo la idea de que el derecho penal del enemigo representa una "excepción consecuente", o lo que es lo mismo, una "consecuencia necesaria" a la que se ve abocado el funcionalismo normativista de Jakobs en su modo de entender la función de la pena ${ }^{27}$.

La normativización del concepto de persona significa en Jakobs que "desde el punto de vista de la sociedad no son las personas las que fundamentan la comunicación personal a partir de si mismas, sino que es la comunicación personal la que pasa a definir los individuos como personas" 28 . De este modo Jakobs transita de Hegel a Luhmann, pasando por C. Schmitt, para fundamentar toda una teoría de la excepción, basada en la dicotomía ciudadano / enemigo.

Toda esta articulación teórica acontece en varios pasos siempre anclados en su punto de partida metodológico -lo que no cambia en su discurso- que van a mi modo de ver desde un primer intento de presentar como descriptivo un discurso penalmente inaceptable desde el punto de vista del Estado de Derecho en el artículo "Derecho penal de ciudadano y Derecho penal del enemigo"29, pasando por su contribución “¿Terroristas como personas en

\footnotetext{
${ }^{24}$ PEÑARANDA. Op. cit., p. 318.

${ }^{25}$ VON HIRSCH, Andrew. Censurar y castigar. $1^{\circ}$. ed. Madrid: TROTTA, 1998. 184 p.

${ }^{26}$ CONTRERAS. Op. cit., p. 10.

${ }^{27}$ CRESPO, Eduardo Demetrio. Del Derecho Penal liberal al Derecho penal del enemigo. In: Revista de derecho penal e criminología, Espanha, n. 14, p. 87-116, 2004; Idem., El derecho penal del enemigo darf nicht sein! Sobre la ilegitimidad del llamado derecho penal del enemigo y la idea de seguridad. In: CANCIO MELIÁ, Manuel; GÓMEZJARA DÍEZ, Carlos. Derecho penal del enemigo: el discurso penal de la exclusión. Espanha: Edisofer, v. 1, 2006. p. 473-510.

${ }^{28}$ JAKOBS, Günther. Sociedad, norma y persona en una teoría de un Derecho penal funcional. Tradução de Manuel Cancio Meliá e Bernardo Feijóo Sánchez. $1^{\circ}$. ed. Madrid: Civitas, 1996. 85p.

${ }^{29}$ JAKOBS, Günther. Derecho penal del ciudadano y Derecho penal del enemigo. In: Derecho penal del enemigo, Madrid: Civitas, p. 19, 2003 a.
} 
Derecho?"30, y el ulterior "¿Derecho penal del enemigo? Un estudio acerca de los presupuestos de la juridicidad" 31 .

No es este el momento de abordar con detalle todas las perspectivas de discusión a que se ha prestado este lamentable concepto, para lo que nos remitimos a trabajos anteriores y a la amplia bibliografía aparecida entretanto ${ }^{32}$, pero sí de fijarnos en la íntima vinculación y desarrollo que lleva desde la prevención general positiva sistémica al derecho penal del enemigo mediante la propia normativización (abstracción) del concepto de persona.

Como es sabido en el segundo de los artículos mencionados Jakobs formula claramente la siguiente tesis: un derecho penal del enemigo es lícito (darf sein) en el marco de lo imprescindible, porque de lo contrario el Estado (cuya vigencia no puede ser entendida de un modo abstracto) se vendría a pique. Que la actual concepción de Jakobs, a diferencia de lo sostenido en 1985 , no es descriptiva, sino que ha sufrido una evolución progresivamente encaminada a la defensa del Derecho penal del enemigo bajo determinadas condiciones, es algo que está fuera de duda. Paradójicamente, y pese a la rotundidad de sus afirmaciones, cuando el profesor Jakobs hubo de afrontar la objeción (planteada en la discusión que tuvo lugar tras su ponencia en Frankfurt Oder el 08 de mayo de 2005) acerca del peligro que implica una teoría capaz de legitimar un Derecho penal excepcional al margen del Estado de Derecho, el autor contestó que su planteamiento era en un porcentaje del $98 \%$ únicamente descriptivo.

Parecía entonces que se trataba de nuevo más bien de evitar que se produzca una "contaminación" de las características propias del Derecho penal del enemigo al resto del Derecho penal. Pero se jugaba aquí en realidad en el carácter ambiguo del concepto, que admite diversos usos según el contexto. A la discusión sobre el carácter descriptivo o prescriptivo de la fórmula del llamado "derecho penal del enemigo" subyace a su vez una cuestión relativa a la teoría del derecho. En virtud de la falacia realista imperante en la cultura jurídica de corte hegeliano según la cual "lo que es real es racional", se pasa por alto la distinción metalingüística entre lo "descriptivo" y lo "normativo", inexistente en la cultura jurídica y política funcionalista ${ }^{33}$. Como con acierto ha subrayado Ferrajoli, se presenta por esta vía como legítimo un concepto que en realidad representa una contradicción en los términos o la negación misma del derecho penal, dado que la figura del enemigo pertenece en realidad a la lógica de la guerra, que es en esencia la negación del derecho ${ }^{34}$.

Esto no puede impedir ver que no se trata más que de un nuevo desarrollo en su pensamiento metodológico, en el cual el criterio del bien jurídico como concepto delimitador de la intervención penal pierde toda relevancia, y se sustituye por la función preventivogeneral positiva de la "estabilización de la norma". El propio Jakobs ya reconocía en su trabajo

\footnotetext{
${ }^{30}$ Idem., ¿Terroristas como personas en Derecho?. In: CANCIO MELIÁ, Manuel; GÓMEZ-JARA DíEZ, Carlos. Derecho penal del enemigo: el discurso penal de la exclusión. Espanha: Edisofer, 2006 a. p. 77-92. v. 2.

${ }^{31}$ Idem., ¿Derecho penal del enemigo? Un estudio acerca de los presupuestos de la juridicidad. In: CANCIO MELIÁ, Manuel; GÓMEZ-JARA DÍEZ, Carlos. Derecho penal del enemigo: el discurso penal de la exclusión. v. 2. Espanha: Edisofer, p. 93-116, 2006 b.

${ }^{32}$ Vid. especialmente, MUÑOZ CONDE, Francisco. De nuevo sobre el derecho penal del enemigo. $1^{\circ}$. ed. Buenos Aires: Editora Hammurabi, 2005. 168 p.; CANCIO MELIÁ, Manuel; GÓMEZ-JARA DIEZ, Carlos. Derecho Penal del Enemigo: el discurso penal de la exclusión. Espanha: Edisofer, 2006. v. 1.; ZAFFARONI, Eugenio Raúl. El enemigo en el derecho penal. Madrid: Dykinson, 2006; FERRAJOLI, Luigi. El derecho penal del enemigo y la disolución del derecho penal. In: Nuevo Foro Penal, Colombia, n. 69, p. 13-31, 2006.

${ }^{33}$ FERRAJOLI, Luigi. El derecho penal del enemigo y la disolución del derecho penal. In: Nuevo Foro Penal, Colombia, n. 69, 2006. p. 17

34 Ibid., p. 16.
} 
del año 1985 sobre la tentativa que en situaciones excepcionales la vigencia de la norma podía verse amenazada si no se entra en la esfera privada del autor, aunque dichas normas debieran quedar separadas del "Derecho penal del ciudadano" para no contaminarlo. Se trataba, en todo caso, sólo de una aparente contradicción porque lo que se pone de relieve en realidad es que de su modelo de pensamiento se extrae consecuentemente la necesidad de recurrir a un sistema excepcional para determinados supuestos (sujetos que no ofrecen seguridad cognitiva) que no encajan en el artificial edificio conceptual normativo del autor.

Merece la pena, además, observar que la capacidad legitimadora de la teoría del derecho penal del enemigo puede llegar a abarcar ciertamente un segmento más amplio que el que se deriva en primera instancia del estado actual de un determinado ordenamiento jurídico. Si este fuera el caso, apelar al carácter meramente descriptivo de una construcción que en el fondo ofrece cobertura teórica ("justificación") para esa realidad que dice describir se convierte sólo en un argumento circular. Pero, como señalamos más arriba, punto de llegada es toda una "teoría de la excepción penal", que constituye a su vez un esclarecedor manifiesto de su propia teoría del derecho, del derecho penal y de la pena, y de las bases de la teoría del Estado que la sustentan ${ }^{35}$.

Jakobs habla en el último de los artículos mencionados de los "presupuestos de la juridicidad" y con ello de sus límites. En su opinión se trata solo de describir a quién el sistema jurídico trata como enemigo, de una mera constatación. Para Jakobs hay que distinguir entre un Derecho postulado, un Derecho-modelo y la estructura normativa real de una sociedad. En su opinión ser persona en derecho es algo sinalagmático, ya que requiere que el otro participe, y por otro lado, postular un derecho y tener realmente ese derecho no es lo mismo.

Siempre según este autor "las normas necesitan de una cimentación cognitiva si se pretende que ofrezcan orientación, no basta con que puedan ser expuestas como correctas o plausibles, sino que es necesario que se establezcan"36. "Todo aquel que prometa de modo más o menos confiable fidelidad al ordenamiento jurídico tiene derecho a ser tratado como persona en derecho, quien no preste esa promesa de modo creíble será tendencialmente heteroadministrado"37. "Una sociedad que realmente acontece no puede prescindir de una exclusión más o menos amplia de sus adversarios recalcitrantes. Sin embargo el Derecho penal del enemigo sigue siendo Derecho en la medida en que vincula a su vez a los ciudadanos, más exactamente, al Estado, sus órganos y funcionarios, en la lucha contra los enemigos. Lo que sucede es que el Derecho penal del enemigo no es una regulación para la aniquilación ilimitada, sino en un Estado de Derecho administrado con inteligencia, una ultima ratio que es aplicada conscientemente en cuanto excepción, como algo que no es idóneo para su uso

\footnotetext{
35 JAKOBS. 2006 c. así como la introducción de Cancio Meliá y Feijoo Sánchez, en la que los autores aceptan que el proceso de reformulaciones de la teoría de la pena de Jakobs ha conocido tres fases: a) una primera más psicologicista (hasta principios de los años noventa), en la que la pena se entiende en sentido preventivo; b) una segunda caracterizada por la identificación de su teoría de la pena con un concepto funcional de retribución; c) y una tercera basada en una recognitivización de la teoría de la pena. Esta última, además del dolor penal como presupuesto del funcionamiento de la pena, incorpora el derecho penal del enemigo como reacción frente a los sujetos imputables peligrosos.

${ }^{36}$ JAKOBS, Günther. ¿Derecho penal del enemigo? Un estudio acerca de los presupuestos de la juridicidad. In: CANCIO MELIÁ, Manuel; GÓMEZ-JARA, Carlos. Derecho Penal del enemigo: el discurso penal de la exclusión. v. 2. Espanha: Edisofer, p. 93-116, 2006 b.

${ }^{37}$ Ibid., p. 106.
} 
permanente"38. En una reciente contribución concluye "el derecho penal del enemigo es un derecho de la excepción y como tal debe designarse para evitar confusiones con el derecho penal del ciudadano. Si el Derecho penal del enemigo es necesario es algo que depende del entorno del Estado de derecho, esto es, también de sus enemigos" ${ }^{\prime \prime}$.

En opinión de Portilla Contreras la distinción entre amigo-enemigo de Schmitt es el soporte de la separación entre el Derecho penal del ciudadano y el Derecho penal del enemigo. Para este autor "sin duda alguna, Jakobs asume la teoría de C. Schmitt no solo cuando, como él, atribuye al Estado el ius belli, esto es, la posibilidad de determinar quién es el enemigo y combatirlo, de declarar la guerra y, en consecuencia de disponer de la vida de las personas; también cuando revela que la lucha contra el enemigo se despliega fuera de la Constitución civil, esto es, en el estado de naturaleza" 40 .

Sin embargo, como destaca Beck en su obra "Der kosmopolistische Blick" ${ }^{41}$, Schmitt subraya en el "Concepto de lo político" que se expresa el respeto al enemigo precisamente porque se le reconoce como tal y no como delincuente ${ }^{42}$. En este sentido es claro que en Jakobs se trata justamente de lo contrario, en conceder al "delincuente" la categoría de "enemigo" al que hay que combatir privándole de cualquier derecho, y por encima de todo, de su capacidad de actuar ${ }^{43}$.

\section{Jakobs justamente no desconoce este punto crucial:}

"El concepto de Schmitt no se refiere a un delincuente sino al hostis, al otro; dentro del Estado, sólo cuando se llega a una guerra civil existe una confrontación política en el sentido de Schmitt. En cambio el enemigo del Derecho penal del enemigo es un delincuente de aquellos que cabe suponer que son permanentemente peligrosos, un inimicus. No es otro, sino que debería comportarse como un igual, y por ello se le atribuye culpabilidad jurídicopenal, a diferencia del hostis de Schmitt. Si en mis consideraciones me hubiera referido a Carl Schmitt, ello habría constituido una cita radicalmente fallida" ${ }^{44}$.

Esto no significa, sin embargo, que pueda eludir tan fácilmente la vinculación al pensamiento schmittiano, sino que su proximidad al mismo hay que buscarla no tanto en el diagnóstico, sino, en palabras de Prieto Navarro, en algo previo, en "su apuesta por el carácter

\footnotetext{
38 Ibid., p. 107.

${ }^{39}$ Idem. An der Grenzen rechtlicher Orientierung: Feindstrafrecht. In: Nullum ius sine scientia. Festschrift für Jaan Sootak zum 60. Geburtstag am 16. Juli 2008, Talinn: Juura, p. 131-153, 2008. p. 153.

${ }^{40}$ CONTRERAS, Guillermo Portilla. Los excesos de formalismo jurídico neofuncionalista en el normativismo del derecho penal. In: Revista General de Derecho Penal, Espanha, n. 4, p. 8, 2005.

${ }^{41}$ BECK, Ulrich. Der kosmopolitische Blick oder: Krieg ist Frieden. Alemanha: Brochuras, p. 205, 2004.

${ }^{42}$ En dicha obra puede leerse: "También en esa otra forma moderna de hacer la guerra ahora, la llamada guerra fría, se quiebran todos los ejes conceptuales que soportaban antes el sistema tradicional de delimitar y regular la guerra. La guerra fría se burla de todas las distinciones clásicas entre guerra, paz, neutralidad, entre política y economía, entre combatiente y no combatiente; lo único que mantiene es la distinción entre amigo y enemigo, cuya estricta consecuencia constituye su origen y esencia" - SCHMITT, Carl. El concepto de lo político: texto de 1932 con un prólogo y tres corolarios. Madrid: Versión de R. Agapito, 1998.

${ }^{43}$ CRESPO, Eduardo Demetrio. El derecho penal del enemigo darf nicht sein! Sobre la ilegitimidad del llamado derecho penal del enemigo y la idea de seguridad. In: CANCIO MELIÁ, Manuel; GÓMEZ-JARA DíEZ, Carlos. Derecho penal del enemigo: el discurso penal de la exclusión. Espanha: Edisofer, v. 1, p. 486, nota 41, 2006.

${ }_{44}$ JAKOBS, Günther. ¿Derecho penal del enemigo? Un estudio acerca de los presupuestos de la juridicidad. In: CANCIO MELIÁ, Manuel; GÓMEZ-JARA, Carlos. Derecho Penal del enemigo: el discurso penal de la exclusión. v. 2. Espanha: Edisofer, p. 108-109, 2006 b.
} 
auténticamente aleccionador del caso excepcional frente a la normalidad del cumplimiento de la norma" 45 . Dicho de otro modo, la teoría del "derecho penal del enemigo", sobre la base de la distorsión del lenguaje, procede a la disolución misma del derecho mediante la criminalización del enemigo y la militarización de la justicia ${ }^{46}$.

\section{CONCLUSIONES}

El funcionalismo normativista de Günther Jakobs mediante la progresiva renormativación de los conceptos, la pérdida del horizonte valorativo, y la falta de límites, ha construido un método de pensamiento absolutamente formalizado, alejado de la realidad, y con capacidad de adaptación a cualquier sistema jurídico.

El último estadio de evolución de dicho método, que toma como punto de partida la prevención general positiva entendida como estabilización de la vigencia de las normas, ha desembocado en el llamado "derecho penal del enemigo". A la pregunta decisiva acerca de la legitimidad de un tal derecho se responde por su principal artífice teórico afirmativamente, bien que en el "marco de lo necesario". Esta afirmación se hace posible a su vez por la relativización del propio concepto del Estado de Derecho con el argumento de que dicho concepto no puede interpretarse como vigencia abstracta, sino concreta.

Como se ha visto el "derecho penal del enemigo" representa una consecuencia de una metodología jurídico-penal con un enorme potencial de legitimación de toda clase de medidas contrarias al Estado de Derecho. Frente a esto hay que alzar la voz en el plano científico y recordar que los Derechos Humanos, y su salvaguarda, como la separación de poderes o el principio democrático, son ciertamente elementos constitutivos del Estado de Derecho. Como advierte E. Díaz, no todo Estado es Estado de Derecho (no basta con un Estado administrativo de Derecho), sino que el Estado de Derecho supone la institucionalización jurídica de la democracia política, que encuentra en los Derechos Humanos su verdadera razón de $\operatorname{ser}^{47}$.

Desde el punto de vista aquí adoptado no es posible "normativización" alguna del concepto de persona que permita distinciones tales entre "personas" y "no personas" ("individuos" o "fuentes de peligro" a las que el derecho debe heteroadministrar). El Estado de Derecho tampoco se pone caprichosamente en juego, como dice Jakobs, por no adoptar un tal Derecho penal del enemigo. Al contrario, debe ceñirse a un Derecho penal del hecho respetuoso con los límites, principios y garantías que le son propios. Allí donde se detecten trasvases de dichos límites, estos deben denunciarse y subsanarse. Solo desde el respeto a los Derechos Humanos se puede configurar el vínculo entre el sery el deber ser del Derecho penal. Los Derechos Humanos han de ser, en último término, la barrera infranqueable a toda pretensión político-criminal, filosófico-política, filosófico-jurídica, sociológica o dogmática.

\footnotetext{
${ }^{45}$ PRIETO NAVARRO, Evaristo. Excepción y normalidad como categorías de lo político. In: CANCIO MELIÁ, Manuel; POZUELO PÉREZ, Laura. Política criminal en vanguardia: Inmigración clandestina, terrorismo, criminalidad organizada, Madrid: Thomson-Civitas, p. 130, 2008.

${ }^{46}$ FERRAJOLI. Op. cit., p. 20-21.

${ }^{47}$ DÍAZ, Elías. Estado de derecho y recechos humanos. In: BETEGÓN CARRILLO, Jerónimo; LAPORTA SAN MIGUEL, Francisco Javier; SANCHÍS, Luis Prieto. Constitución y Derechos Fundamentales, Madrid: [s.n.], p. 17, 2004.
} 


\section{REFERÊNCIAS}

BARATTA, Alessandro. Integración-prevención: una nueva fundamentación de la pena dentro de la teoría sistémica. In: RevicyhLUZ: Revistas Científicas e Humanísticas, Venezuela, n. 15, 1987.

BAURMANN. Vorüberlegungen zu einer empirischen Theorie der positive Generalprävention. Alemanha: Heidelberg, Decker, 1994.

BECK, Ulrich. Der kosmopolitische Blick oder: Krieg ist Frieden. Alemanha: [s.n.], 2004.

CANCIO MELIÁ, Manuel; GÓMEZ-JARA DIEZ, Carlos. Derecho Penal del Enemigo: el discurso penal de la exclusión. Espanha: Edisofer, v. 1, 2006.

CRESPO, Eduardo Demetrio. Prevención general e individualización judicial de la pena, Salamanca: Ediciones Universidad de Salamanca, 1999.

. Del Derecho Penal liberal al Derecho penal del enemigo. In: Revista de derecho penal e criminología, Espanha, n. 14, 2004.

El derecho penal del enemigo darf nicht sein! Sobre la ilegitimidad del llamado derecho penal del enemigo y la idea de seguridad. In: CANCIO MELIÁ, Manuel; GÓMEZ-JARA DÍEZ, Carlos. Derecho penal del enemigo: el discurso penal de la exclusión. Espanha: Edisofer, v. 1, 2006.

Culpabilidad y fines de la pena: con especial referencia al pensamiento de Claus Roxin. In: Revista Derecho Penal Contemporáneo, Bogotá, n. 25, 2008.

CONTRERAS, Guillermo Portilla. Los excesos de formalismo jurídico neofuncionalista en el normativismo del derecho penal. In: Revista General de Derecho Penal, Espanha, n. 4, 2005.

DÍAZ, Elías. Estado de derecho y recechos humanos. In: BETEGÓN CARRILLO, Jerónimo; LAPORTA SAN MIGUEL, Francisco Javier; SANCHÍS, Luis Prieto. Constitución y Derechos Fundamentales, Madrid: [s.n.], 2004.

FERRAJOLI, Luigi. El derecho penal del enemigo y la disolución del derecho penal. In: Nuevo Foro Penal, Colombia, n. 69, 2006.

GARCÍA AMADO, Juan Antonio. ¿Dogmática penal sistémica? Sobre la influencia de Luhmann en la teoría penal. In: Revista DOXA, Alicante, n. 23, 2000.

HABERMAS, Jürgen. Facticidad y validez: sobre el derecho y el Estado democrático de derecho en términos de teoría del discurso. 5. ed. Madrid: TROTTA, 2010.

HIRSCH, Hans Joachim et al. El principio de culpabilidad y su función en el Derecho Penal. In: Revista Peruana de Ciencias Penales, Lima, n. 5, jan. 1995.

JAKOBS, Günther et al. Sociedad, norma y persona en una teoría de un Derecho penal funcional. Tradução de Manuel Cancio Meliá e Bernardo Feijóo Sánchez. $1^{\circ}$. ed. Madrid: Civitas, 1996.

. Criminalización en el estado previo a la lesión de un bien jurídico. In: JAKOBS, Estudios de Derecho Penal. Tradução de Peñaranda Ramos et al. Madrid: Civitas, 1997 a.

. Norm, Person, Gesellschaft. Vorüberlegungen zu einer Rechtsphilosophie, Berlin: [s.n.], 1997 b. 
. Derecho penal. Parte General. Fundamentos y teoría de la imputación. Tradução de Joaquín Cuello Contreras e José Luis Serrano González de Murillo, 2 ed., Madrid: Marcial Pons, 1997 c.

. Derecho penal del ciudadano y Derecho penal del enemigo. In: Derecho penal del enemigo, Madrid: Civitas, p. 19, 2003 a.

. Sobre la normativización de la dogmática jurídico-penal. Tradução de Cancio Meliá e Feijóo Sánchez, Madrid: Civitas, 2003 b.

. La autocomprensión de la Ciencia del Derecho penal frente a las exigencias de su tiempo. Tradução de T. Manso. In: MUÑOZ CONDE, Francisco, La Ciencia del Derecho Penal ante el nuevo milenio, Valencia: [s.n.], 2004.

. ¿Terroristas como personas en Derecho?. In: CANCIO MELIÁ, Manuel; GÓMEZJARA DÍEZ, Carlos. Derecho penal del enemigo: el discurso penal de la exclusión. Espanha: Edisofer, v. 2, 2006 a.

- ¿Derecho penal del enemigo? Un estudio acerca de los presupuestos de la juridicidad. In: CANCIO MELIÁ, Manuel; GÓMEZ-JARA, Carlos. Derecho Penal del enemigo: el discurso penal de la exclusión. Espanha: Edisofer, v. 2, 2006 b.

Civitas, 2006 c.

. La pena estatal: significado y finalidad. Tradução de José Feijoo Sánchez. Madrid:

. An der Grenzen rechtlicher Orientierung: Feindstrafrecht. In: Nullum ius sine scientia. Festschrift für Jaan Sootak zum 60. Geburtstag, Talinn: Juura, 2008.

JAKOBS, Günther; MELIÁ, Manuel Cancio. Derecho penal del enemigo, Madrid: Civitas, 2003.

KUHLEN, Lothar. Zum Strafrecht der Risikogesellschaft. In: Goltdammer's Archiv für Strafrecht: GA. Heidelberg: Decker, 1994.

LESCH. Der Verbrechensbegriff. Grundlinien einer funktionalen Revision, Köln. Berlin. Bonn. München: Heymann, 1999.

LUHMANN, Niklas. Normen in soziologischer Perspektive. In: Soziale Welt. Alemanha: [s.n.], v. 20, 1969.

. Rechtssoziologie, $3^{\circ}$ ed., Opladen: Westdt. Verl, 1987.

MUÑOZ CONDE, Francisco. De nuevo sobre el derecho penal del enemigo. $1^{\circ}$. ed. Buenos Aires: Editora Hammurabi, 2005.

MÜSSIG, Bernd. Schtuz abstrakter Rechtsgüter und abstrakter Rechtsgüterschtuz. Alemanha: Frankfurt Am Main: P. Lang, 1994.

PEÑARANDA RAMOS, Enrique. Sobre la influencia del funcionalismo y la teoría de sistemas en las actuales concepciones de la pena y del concepto de delito, San Vicente del Raspeig: Universidad de Alicante, 2000.

PRIETO NAVARRO, Evaristo. Teoría de sistemas, funciones del Derecho y control social: perspectivas e imposibilidades para la dogmática penal. In: Revista DOXA, Alicante, n. 23, 2000. 
. Excepción y normalidad como categorías de lo político. In: CANCIO MELIÁ, Manuel; POZUELO PÉREZ, Laura. Política criminal en vanguardia: Inmigración clandestina, terrorismo, criminalidad organizada, Madrid: Thomson-Civitas, 2008.

SCHMITT, Carl. El concepto de lo político: texto de 1932 con un prólogo y tres corolarios. Madrid: Alianza, 1998.

SCHÜNEMANN, Bernd. El propio sistema de la teoría del delito. In: InDret: Revista para el análisis del derecho, Barcelona, v.1, fev. 2008.

SILVA SÁNCHEZ, Jesús Maria. Introducción, en B. Schünemann, El sistema moderno del Derecho penal: cuestiones fundamentales, Madrid: Tecnos, 1991.

VON HIRSCH, Andrew. Censurar y castigar. Editorial Trotta, 1998.

ZAFFARONI, Eugenio Raúl. El enemigo en el derecho penal. Madrid: Dykinson, 2006. 